\title{
O homem com a câmera (1929) como um filme-diário
}

\author{
Luis Felipe Gurgel Ribeiro Labaki' \\ https://orcid.org/0000-0001-6288-5287 \\ I - Universidade de São Paulo. \\ São Paulo (SP). Brasil.
}

Resumo: Ainda que o cineasta soviético Dziga Viértov (1896-1954) não reali-
zasse filmes-diário em um sentido estrito, este artigo investiga a forma pela
qual parte de sua obra da década de 1920 pode ser vista como atravessada
por uma noção, ainda que difusa, de diário. Ela se expressaria tanto por meio
de menções diretas a diários em seus filmes e escritos quanto por meio de
uma contínua intenção ora concretizada, ora apenas planejada, de autorre-
presentação dos kinocs nos trabalhos realizados pelo grupo - uma prática
que sugere a possibilidade de vermos ao longo de filmes, esboços e projetos
não-realizados a construção de um fragmentário "diário profissional coletivo".
Nesse sentido, O homem com a câmera (1929) é analisado pelo prisma de seu
subtítulo “Excerto do diário de um cinegrafista", uma fórmula cuja importância,
historicamente, foi relativizada talvez em demasia pelos estudos viertovianos.

Palavras-chave: Dziga Viértov; filme-diário; cinema documentário.

\begin{abstract}
Man with a Movie Camera (1929) as a diary film - Even though Soviet filmmaker Dziga Vertov (1896-1954) didn't produce diary films in a strict sense, this paper investigates how part of his oeuvre from the 1920s can be seen as permeated by a notion, albeit a diffuse one, of diary. This would be expressed both by means of direct references to diaries in his films and writings and by a continuous intent - at times accomplished, at others only planned - of self-representation by the kinoks in the works produced by the group, a practice that suggests us the possibility of seeing, throughout films, sketches and unrealized projects, the construction of a fragmentary "collective professional diary". In this sense, Man with a Movie Camera (1929) is here analyzed through the prism of its subtitle "An excerpt from a cameraman's diary", a formula whose importance has been historically downplayed in Vertovian studies.
\end{abstract}

Keywords: Dziga Vertov; film diary; documentary cinema. 


\section{Introdução}

Ao pensarmos em filmes-diário, dificilmente os trabalhos do cineasta Dziga Viértov estariam entre os primeiros lembrados. Se não por outras razões, por uma mera questão cronológica. Ainda que, já em 0 espírito do cinema (1930), o húngaro Béla Balázs tenha especulado brevemente a respeito das perspectivas abertas pela ideia de um diário filmado - em um texto que retomarei mais adiante (BALÁZS, 2010, p. 155) -, o filme-diário enquanto conceito se estabelece de maneira mais sistemática sobretudo a partir do cinema de vanguarda norte-americano das décadas 1950 e 1960, perpassando obras de artistas como Marie Menken, Stan Brakhage e, de modo central, Jonas Mekas (SITNEY, 2002).

Sob essa ótica, Viértov não realizava filmes-diários num sentido estrito - se é que podemos falar de filmes-diário em algum sentido estrito -, e, apesar de possuir uma câmera Debrie Sept (que Ihe fora enviada de Paris por Aleksándr Rôdtchenko, em 1925), é improvável que tenha mantido seu próprio "diário em filme", resultado de filmagens domésticas acumuladas ao longo dos anos. Suas reiteradas e mal-sucedidas tentativas de organizar um laboratório criativo, no qual estaria à sua disposição uma filmoteca pessoal contendo as versões autorais de seus filmes e também aquilo que chamava de "esboços criativos em película" — sobras de seus processos de montagem ou materiais ainda inéditos que poderiam ser incluídos em algum projeto futuro -, revelam sua dificuldade em manter e acessar até mesmo cópias de seus trabalhos finalizados.

O cineasta tampouco buscou delinear de maneira inequívoca seu entendimento do que poderia ser, afinal, um filme-diário, deixando apenas comentários lacônicos a esse respeito. Mas, apesar disso, irei investigar neste artigo a forma pela qual parte de sua obra dos anos 1920 pode ser vista como atravessada por uma noção, ainda que bastante difusa, de diário. Ela se expressaria tanto por meio de algumas menções diretas feitas em seus filmes e escritos a diários (sejam eles reais ou fictícios), quanto por meio de uma contínua intenção ora concretizada, ora apenas planejada, de autorrepresentação dos kinocs $^{2}$ nos trabalhos realizados pelo grupo, uma

1 Utilizo aqui a distinção entre "diário em filme" e "filme-diário" proposta por David E. James (2013, p. 167-168): "Tanto quanto um diário escrito, um diário feito na forma de filme privilegia o autor, o processo e o momento de composição [...] Trata-se de um evento privado no qual o consumo, em especial o consumo por parte de outros, é ilícito [...] Mas um filme-diário se encontra numa economia de filmes, economia esta que privilegia o artefato completo como um todo, o momento da projeção, o público espectador e, de uma forma ou de outra, o valor de troca".

2 Contração de "kinó" (cinema) e "ôko" (palavra russa arcaica para olho), era assim que Viértov se referia aos membros de seu grupo de trabalho, o Cine-Olho (Kino-Glaz). 
prática que sugere a possibilidade de vermos ao longo de filmes, esboços e projetos não-realizados a construção de um fragmentário "diário profissional coletivo". Para tanto, partirei de um contato direto com fontes fílmicas e textuais do cineasta para buscar compreender como a ideia de um diário filmado teria sido trabalhada por Viértov ao longo dos anos.

Não por acaso, o centro dessa discussão será o último filme feito por Viértov nessa década: O homem com a câmera (1929), ao mesmo tempo a mais eloquente manifestação de estratégias metalinguísticas experimentadas em obras anteriores e único filme do cineasta a se apresentar de maneira explícita como um diário - apesar de não ser, como veremos, o primeiro a flertar com essa ideia. Esse aspecto, no entanto, tem sido relativamente pouco explorado nos estudos viertovianos, merecendo uma nova atenção.

\section{A importância de um subtítulo}

Análises fundamentais e já clássicas do filme, como os trabalhos de Annette Michelson (1972) e Vlada Petrič (1987), assim como estudos mais recentes (ROBERTS, 2000; HICKS, 2007), não dedicam muitas palavras ao fato de o "manifesto em celulóide" do cineasta soviético se definir em sua cartelatítulo como um "Excerto do diário de um cinegrafista" ${ }^{3}$. Já para estudiosos do filme-diário, O homem com a câmera parece desempenhar um papel discreto, representando algo como um "antepassado distante". Nesse sentido, é interessante notar como David E. James (2013, p. 181, rodapé $n^{\circ 20}$ ), ao escrever sobre Walden (Diários, Notas e Esboços) (dir. Jonas Mekas, 1969), afirma ver semelhanças consideráveis entre certos princípios de trabalho de Mekas e de Viértov, mas curiosamente nada diz a respeito de O homem com a câmera.

Uma das possíveis razões para a relativa pouca atenção que o termo "excerto do diário de um cinegrafista" tem recebido pode ser uma impressão de que o subtítulo talvez não devesse ser tomado como um elemento com força estruturante. É, por exemplo, o que sugere Jeremy Hicks ao considerá-lo apenas um dentre diversos "modelos genéricos" evocados por Viértov para se referir à obra, como "experimento", "filme de produção" e "sinfonia". Para Hicks (2007, p. 66), esses seriam apenas "veículos para o mesmo conceito central de um filme sobre fazer filmes" - sendo talvez, se seguirmos essa lógica, intercambiáveis em sua relativa desimportância. 
Viértov era, de fato, um prolífico criador de "subgêneros" para seus "cineobjetos" [kino-viêschi]. Grande parte de seus trabalhos possui, em seus títulos e subtítulos, termos que sugerem aproximações entre o objeto fílmico e práticas distintas. Estas podem ser artísticas - como o "cine-poema" em A sexta parte do mundo (1926) ${ }^{4}$, a sinfonia em Entusiasmo: Sinfonia de Donbass (1930), a Canção de ninar (1937) e os Três cantos sobre Lênin (1934) -, mas podem derivar também de outros campos: termos associados aos serviços de inteligência, como a "missão de reconhecimento" (O Cine-Olho em sua primeira missão de reconhecimento: $1^{\circ}$ episódio do ciclo 'A vida apanhada de surpresa', 1924) e o "relatório" (Kino-Pravda N²0 em 5 relatórios de cine-observadores, 1924), ou ainda a ideia de "corrida" - utilizada nas edições No 18 e No 19 de Kino-Pravda (ambas de 1923) e no já citado $A$ sexta parte do mundo.

Chamam atenção no trabalho de Viértov a quantidade de gêneros "cineficados" por meio desse procedimento, assim como a persistência dessa prática: o cineasta seguiria propondo novas nomenclaturas até seus últimos projetos, como os não-realizados “Um conto sobre um gigante" (1940)5, apresentado como um "roteiro científico-fantástico, artístico-documentário" (VIÉRTOV, 2008, p. 365) e a "Galeria de cine-retratos" (VIÉRTOV, 2004, p. 449), de 1944. Em escritos e falas das décadas de 1930 e 1940, ganham espaço parágrafos retrospectivos que, apresentando inventários desses subgêneros, buscam reforçar a diversidade formal de sua obra:

[...] Há cine-crônicas comuns (Kino-Nediêlia), crônicasrelâmpago (cine-telegramas), filmes históricos [...] cineeditoriais, cine-feuilletons, cine-versos [...] cine-charges [...], filmes para diferentes campanhas e festejos, estudos experimentais [...], grandes poemas, como Cine-Olho, Avante, soviete!, $A 6^{a}$ parte do mundo, 0 décimo primeiro ano, canções sem palavras, como $O$ homem com a câmera e sinfonias sonoras, ruidosas, como Entusiasmo [...] (VIÉRTOV, 2008, p. 282).

\footnotetext{
4 Apesar de não constar nos créditos de abertura das principais cópias do filme hoje em circulação, a definição "Um cine-poema em 6 partes" aparece no convite para uma sessão-teste promovida pelo Sovkinó em 6 de outubro de 1926. Ver o documento no acervo do Österreischiches Filmmuseum: <https://bit.ly/31YjhKO> (Último acesso: 24/03/2021). Em diversos artigos posteriores à realização do filme, Viértov voltaria a se referir à obra como um "poema".

5 Este projeto é discutido em maiores detalhes em: LABAKI, 2016, p. 184-206.

6 A não ser quando indicado, as traduções dos textos de Viértov e demais autores ao longo deste artigo foram realizadas por mim.
} 
Listagens similares feitas em outros textos incluiriam também outros gêneros e, dentre eles, o "cine-diário"7. Ao mesmo tempo, é importante notar que há, nessas passagens, uma considerável liberdade na associação entre obras e gêneros: Viértov não se atém necessariamente aos termos utilizados à época da produção de cada filme, tampouco àqueles inscritos em suas cartelas iniciais. Assim, a "primeira missão de reconhecimento" do Cine-Olho se torna um "grande poema", e O homem com a câmera - definido em uma das versões de seu roteiro como uma "sinfonia visual" e, nos créditos, como "excerto do diário de um cinegrafista" - surge como uma "canção sem palavras".

Mas, se esses inventários retrospectivos, aliados às mudanças ocorridas durante o processo de produção de cada filme (ao longo do qual diferentes possibilidades de estruturação - e, com frequência, de título - eram testadas) parecem confirmar a ideia de relativa intercambialidade desses "modelos genéricos", cabe nos perguntarmos se essa constatação seria válida para, em última análise, desconsiderarmos o papel que, uma vez inscrito na cartela inicial de um filme, cada um desses subgêneros pode desempenhar na apreensão da obra. Afinal, sua presença no objeto fílmico estabelece para o espectador, de imediato, um possível "modo de leitura" (ou melhor, de visionamento). Emblemático disso é o incômodo de Viértov com o fato de $O$ homem com a câmera ter sido exibido em Berlim com uma legenda inicial "idiota, inventada sabe-se lá por quem", que dizia que "o filme mostra um dia em Kíev e em Moscou". Diante disso, diz Viértov, "é claro que o filme inteiro foi visto à luz dessa legenda absurda" (VIÉRTOV, 2008, p. 184). Ou seja: se o próprio filme se apresenta como o "excerto de um diário", por que não buscar compreendê-lo como tal?

Outra possível razão para a "relativa desimportância" do subtítulo pode ser a ausência de comentários a seu respeito nos principais textos de Viértov sobre O homem com a câmera. À época do lançamento do filme, o cineasta enfatizava sobretudo sua dimensão de "experimento de cine-transmissão de fenômenos visuais" e a tentativa de criação de uma "cine-escrita absoluta, baseada em sua total separação da linguagem do teatro e da literatura" (VIÉRTOV, 2008, p. 146-147), apresentando ainda como um dos motes

7 "Devo falar de Viértov como autor-diretor dos primeiros cine-ensaios, cine-estudos, cine-diários [...]?" (VIÉRTOV, 2008, p. 360) e também "Avtobiográfia" (VIÉRTOV, 1996, p. 186). 
da campanha publicitária de lançamento a ideia de que este seria um "filme

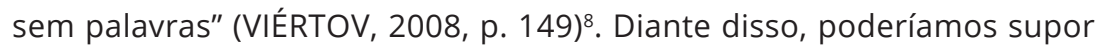
que ressaltar o subtítulo "excerto do diário de um cinegrafista" poderia ser contraproducente, aumentando ainda mais a confusão do público e da crítica diante de um filme já então controverso e que, afinal, apresentava-se como totalmente apartado da literatura.

Mas essa ausência de comentários por escrito não significa que Viértov não tenha abordado a questão em momento algum. Registros de seus pronunciamentos em sessões de $O$ homem com a câmera revelam que, nos embates com o público, o cineasta se referiria repetidas vezes ao caráter de "excerto de um diário" do filme, discutindo inclusive sua importância para a estruturação da obra":

Aqui, o tema foi escolhido de maneira consideravelmente mais restrita: um excerto do diário de um cinegrafista. É mostrado o trabalho do cinegrafista fora do estúdio, uma série de exemplos de seu trabalho [...] Em nosso experimento, são mostrados apenas aqueles instantes da vida que coincidiram com os momentos produtivos do trabalho do cinegrafista, a exibição desses instantes da vida, a escolha desses momentos foi subordinada à tarefa central: um excerto do diário de um cinegrafista, ou exemplos do trabalho do cinegrafista fora do estúdio (VIÉRTOV, 2008, p. 154-155).

Poucos dias antes, em outra exibição, Viértov dissera à plateia que gostaria de apresentar um filme que consistiria em "algo como fragmentos do diário de um cinegrafista", no qual este nos revelaria "os momentos mais interessantes de seu trabalho" (VIÉRTOV, 2008, p. 150). Há também nessas falas uma aproximação clara com a ideia de um "filme de produção" [proizvôdstvenni fílm] (filmes não-ficcionais focados na descrição de um determinado processo produtivo) voltado à realização cinematográfica. Mas é interessante notar que, ao invés de adotar um ponto-de-vista e um título que sugerissem uma abordagem puramente técnica, Viértov decidiu "emoldurar" seu trabalho com um subtítulo que remete a uma escrita - e a um olhar — fundamentalmente subjetivos.

8 Esse aspecto "enganoso" da propaganda de Viértov já foi largamente discutido pela crítica: ver, por exemplo, os comentários de Yuri Tsivian (2004, p. 16) a respeito dos "pôsteres e placas de ruas" que "gritam para nós a toda hora".

9 Vale ressaltar que esses pronunciamentos permaneceram, em sua maioria, inéditos até a publicação da mais recente edição dos escritos de Viértov na Rússia, já nos anos 2000. 


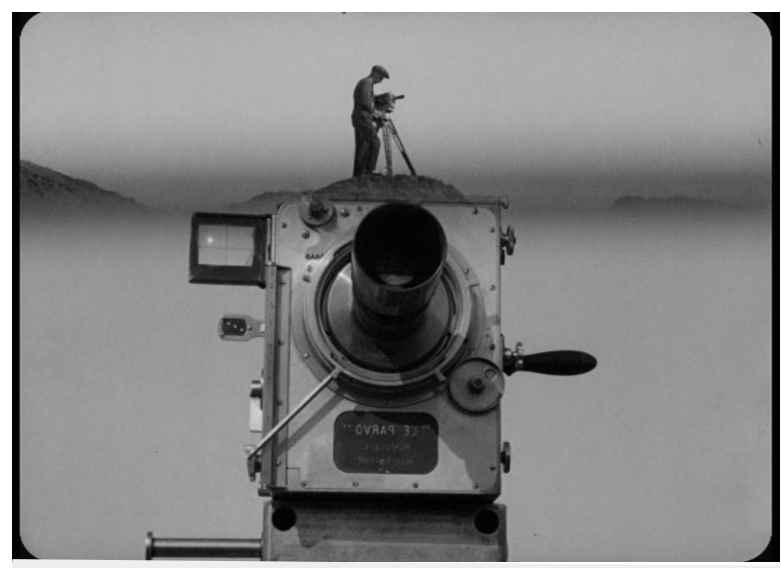

Figura 1. Plano inicial de O homem com a câmera.

Ao mesmo tempo, diante do cinegrafista apresentado logo no plano inicial do filme, poderíamos dizer que cabe ao "excerto do diário de um cinegrafista" também uma função quase sinóptica, sugerindo o protagonismo do "homem com a câmera" - talvez o autor do diário em questão? — que é apresentado ao longo da primeira sequência. No entanto, como nota Vlada Petrič, o filme de Viértov não tarda em advertir o espectador da multiplicidade de pontos de vista que o constituem, e a visão em terceira pessoa, ainda que predominante no prólogo, será constantemente atravessada por quadros que indicarão que "não haverá continuidade diegética entre os ângulos de observação", antecipando "a estrutura cinemática não-ortodoxa de todo o filme", que irá inclusive diluir consideravelmente o suposto protagonismo do cinegrafista, ao mesmo tempo em que incorpora uma série de tomadas realizadas a partir de seu ponto de vista subjetivo. Essa estratégia, por sua vez, será repetida também para outras personagens do emaranhado de "núcleos narrativos isolados" (PETRIČ, 1987, p. 120) da obra, compondo uma verdadeira polifonia de pontos de vista — algo, aliás, presente em trabalhos anteriores de Viértov.

\section{Do diário do pioneiro ao diário do cinegrafista}

Se recuarmos alguns anos, uma pluralidade de vozes narrativas similar pode ser notada em Cine-Olho: A vida apanhada de surpresa, não por acaso 
considerado por Viértov um "antepassado" de O homem com a câmera. No filme, há um momento de diálogo entre duas instâncias narradoras estabelecido precisamente por meio de uma referência a um diário, evocado na tipografia dos intertítulos: trata-se, de um lado, da "voz do Cine-Olho" e, de outro, do "diário do pioneiro"10. Ao longo de todo o filme, além de intertítulos escritos na fonte "construtivista" que marcaria boa parte da produção de Viértov, há cartelas em letra cursiva que emulam a escrita em um caderno, ora animadas de modo que o texto parece se escrever sozinho, ora com a presença de uma mão empunhando uma caneta a escrevê-lo [Figuras 2-5] ${ }^{11}$. Em suas primeiras aparições, o motivo para a mudança de fonte não parece claro; no terceiro rolo do filme, porém, um intertítulo traz um indício de resposta: “Do diário de um pioneiro: se o relógio do nosso clube andasse para trás, o pão voltaria à padaria...". Será então que poderíamos ler todas as cartelas "manuscritas" como sendo referentes às impressões dos jovens pioneiros que acompanham o Cine-Olho em suas "missões de reconhecimento"? A resposta parece ser positiva, especialmente se considerarmos que Viértov utilizaria novamente uma fonte muito similar, cursiva e "infantil", em Kino-Pravda N²0, concluída pouco tempo após Cine-Olho e apresentada em "5 relatórios de cine-observadores" todos eles jovens pioneiros a descrever as atividades do dia.

Sendo esse o caso, a cartela "Do diário de um pioneiro" ganha também ares de mise-en-abyme, no duplo papel de texto que nos informa estarmos diante de um excerto do diário e também do excerto em si, emulado tipograficamente. Não seria uma estratégia estranha a Viértov, que já na sexta edição de Kino-Pravda (1922) fizera algo similar ao iniciar o cinejornal com planos de um projecionista carregando um rolo etiquetado Kino-Pravda $N^{\circ} 6$ no projetor - cena que seria repetida, por sua vez, em O homem com a câmera ${ }^{12}$.

10 Fundada em 1922 e inspirada no escotismo, a organização dos pioneiros era ligada à Juventude Comunista, aceitando crianças de 9 a 14 anos.

11 A mão escrevendo o texto aparece também ao final de cada rolo de filme, aparentemente pontuados por tais cartelas "manuscritas" na versão original. Nas principais cópias disponíveis hoje, só é possível ver a íntegra da cartela ao final do segundo rolo.

12 Em O homem com a câmera, é possível ler o título do filme em ucraniano ('Liudína z aparátom') na lata do rolo sendo carregado pelo projecionista. 

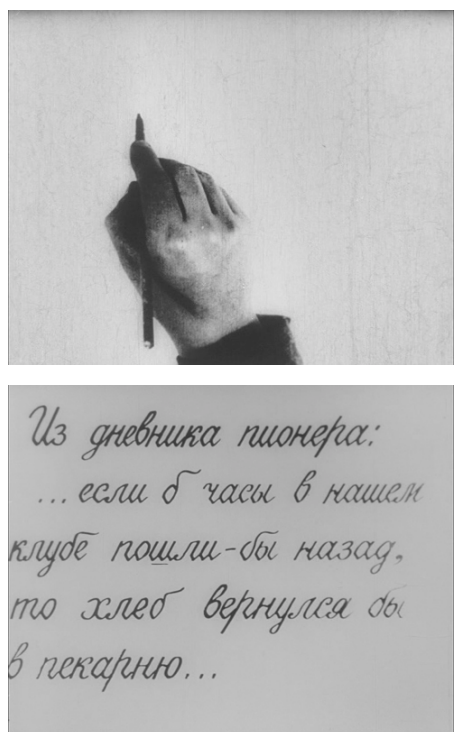
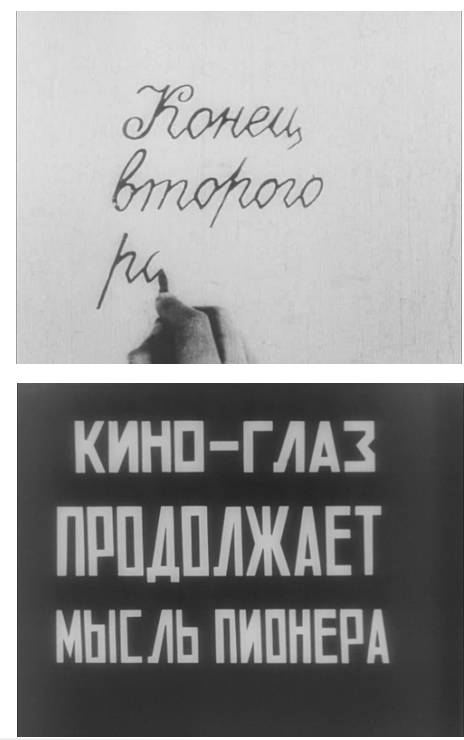

Figuras 2 e 3. Acima: mão escrevendo em quadro a cartela de "Fim do segundo rolo". Figura. 4. Abaixo: o texto que se escreve "sozinho" em "Do diário do pioneiro: se o relógio do nosso clube andasse para trás, o pão voltaria à padaria...". Figura. 5. A cartela seguinte a essa, em outra fonte: "O Cine-Olho dá continuidade ao pensamento do pioneiro".

Neste último filme, porém, não é por meio da tipografia dos intertítulos que o "excerto do diário de um cinegrafista" se configura, tampouco a partir de uma base literária prévia que propusesse de maneira explícita uma aproximação com o gênero diarístico. Não estamos diante, por exemplo, de uma adaptação do Diário de Kóstia Riábtsev (1926), best-seller soviético de Nikolai Ognióv escrito na forma de cadernos íntimos de um jovem estudante que narra sua progressiva tomada de consciência política - personagem, aliás, que não soaria deslocada entre os pioneiros mostrados em Cine-Olho. Viértov efetivamente escreveu para $\mathrm{O}$ homem com a câmera diversos roteiros preliminares contendo muitos elementos reconhecíveis no filme, mas nenhum deles parece incorporar a ideia de estruturá-lo como um diário. O que aparece como linha narrativa central, tanto em esboços (RGALI, f.2091, op.2, ed. khr. 236, II.19-38) quanto na versão enviada ao estúdio VUFKU [Vsieukráinskoe Fotokinoupravliênie, ou Diretoria Pan-Ucraniana de Fotografia e Cinema] (VIÉRTOV, 2004, p. 123-126), é a ideia da jornada de um cinegrafista que, saindo do confinamento do estúdio, confronta-se com a realidade 
da vida "não-atuada" e, aos poucos, torna-se mais apto a se orientar em meio ao aparente caos do mundo visível ${ }^{13}$.

No entanto, apesar de ausente nesses materiais preliminares, "Excerto de um diário" aparece como "título temporário e provisório" em um rascunho manuscrito do roteiro de O décimo primeiro ano (1928) (RGALI, f.2091, op.2, ed. khr.236, l.56), filme anterior de Viértov cuja produção se iniciou, porém, depois da escrita dos primeiros argumentos de O homem com a câmera. Em uma versão datilografada desse mesmo texto, o diário aparece como parte do título provisório "Corredeiras (Excerto de um diário)"; na revisão feita por Viértov, este seria riscado e substituído por uma frase indicando que "o filme irá consistir em um excerto de uma cine-viagem" - definição que, por sua vez, também seria cortada (VIÉRTOV, 2004, p. 489). Não por acaso, essa cineviagem seria descrita em ainda outro esboço de $O$ décimo primeiro ano como "uma viagem do cinegrafista" (RGALI, f.2091, op.2, ed. khr.236, I.53ob.), em termos muito similares aos usados nos rascunhos de 0 homem com a câmera.

Em ambos os projetos, desenvolvidos em paralelo, Viértov lança mão de um mesmo recurso dramatúrgico, estruturando-os em torno de "jornadas do cinegrafista". Mas as semelhanças não param por aí: no diário mantido pelo cineasta durante a filmagem de $O$ décimo primeiro ano, há referências à realização de uma série de quadros indicados como "momentos do cinegrafista" - planos mostrando o trabalho do operador - , apontando que o próprio registro cinematográfico seria tematizado (RGALI, f.2091, op.2, ed.khr.236, II.64-71). Ausentes na versão final do filme, muitos desses planos seriam aproveitados em O homem com a câmera, e John MacKay (2007, p. 44) indaga se Viértov não teria encarado $O$ décimo primeiro ano como uma "mera obrigação contratual" com a VUFKU, da qual ele teria se aproveitado para acumular materiais para seu verdadeiro "projeto autoral".

Algo similar já ocorrera também durante a produção de $A$ sexta parte do mundo (1926). Em um rascunho para os intertítulos do filme, a câmera cinematográfica aparecia como o instrumento que permitiria a união das muitas regiões da URSS (RGALI, f.2091, op.2, ed. khr. 235, I.8-I.10)14, e uma

13 Uma das principais diferenças entre os esboços e o roteiro "final" é que, inicialmente, Viértov propunha que acompanhássemos o cinegrafista em suas férias. No filme, a ideia de uma progressão das habilidades do personagem seria abandonada, mas sua trajetória por diferentes espaços continuaria desempenhando um papel importante.

14 Na versão final do filme, a câmera não é explicitamente tematizada, mas os espectadores da sala de cinema são diretamente interpelados pela "voz do filme" por meio do intertítulo "E vocês, sentados nesta sala de exibição". 
carta enviada por Viértov aos cinegrafistas Samuil Bendiérski e Nikolai lúdin é clara quanto à "necessidade de filmar alguns momentos, dos mais vivos, do trabalho do cinegrafista [...] Quando forem filmar um ao outro, não se filmem sem as câmeras - a câmera deve obrigatoriamente estar bem à vista no quadro [...]" (VIÉRTOV, 1996, p. 194-195). O projeto concreto de O homem com a câmera parece ter surgido justamente poucos dias após o envio dessa carta, ainda em dezembro de 1925, em uma entrada de diário em que o cineasta afirma que um dos filmes produzidos a partir dos materiais sendo captados "pode se chamar: O homem com a câmera, subordinando a este tema todos os demais" (RGALI, f.2091, op.2, ed. khr.235, 1.93). À época, o filme de fato começaria a ser produzido, mas seria interrompido com a demissão de Viértov do órgão estatal Sovkinó em janeiro de $1927^{15}$, sendo retomado na VUFKU apenas após o término de $O$ décimo primeiro ano.

Acompanhando esse processo, vemos o constante interesse de Viértov pelo registro do ato de filmar, mas voltamos também à questão da intercambialidade dos "modelos genéricos" durante a produção dos filmes: em O décimo primeiro ano, Viértov oscila entre "viagem" e "diário" - uma aproximação não exatamente inesperada. O cinema, afinal, já possuía uma longa tradição de travelogues e filmes de expedições, e, como nota Oksana Sarkisova (2007), viagens possuem grande importância na obra de Viértov. No contexto soviético próximo ao cineasta, não podemos ignorar também a crescente valorização de "memórias, biografias, recordações, diários" (BRIK, 2000, p. 226) e diários de viagem promovida por escritores e teóricos da Frente Esquerda das Artes reunidos nas revistas Lef (1923-1925) e Nóvi Lef (1927-1928) ${ }^{16}$. Não é irrelevante, aliás, que o próprio Viértov tenha publicado um curto texto intitulado "O décimo primeiro ano (excertos do diário de filmagem)" ao promover seu novo trabalho (VIÉRTOV, 2008, p. 140) - algo similar ao que seu irmão Mikhail Kaufman já havia feito durante as filmagens de $A$ sexta parte do mundo, com a publicação do artigo "Com a câmera, rumo às estepes (Do diário de um cinegrafista)" (KAUFMAN, 1925, p. 13).

À época, a relação entre Viértov e a Nóvi Lef era turbulenta, especialmente após a recepção do periódico a $O$ décimo primeiro ano. Isso, porém, não apaga o fato de que seu nome figurou por todo o ano de 1927 na lista

15 Viértov foi demitido do Sovkinó em janeiro de 1927 após ser acusado pela diretoria do órgão de ter estourado o orçamento de A sexta parte do mundo.

16 Criadas e editadas por Vladímir Maiakóvski, as revistas representaram importante plataforma de diálogo entre muitos dos principais escritores, teóricos, poetas, artistas plásticos e cineastas da vanguarda artística da URSS nos anos 1920. 
de colaboradores da revista, nem de que seus filmes eram debatidos com frequência na publicação. Imagino que seja essa proximidade que leve Leah Dickerman a afirmar que, ao incluir o subtítulo "Excerto do diário de um cinegrafista" em O homem com a câmera, Viértov teria emoldurado "sua empreitada cinemática em termos factográficos" (2006, p. 140), em referência à ideia de "literatura do fato" discutida pelos autores da Lef. No entanto, apesar de pertencentes a um mesmo "campo de ideias", me parece que o "excerto do diário" proposto pelo filme não se configura em termos exatamente lefistas. Isso porque Viértov se refere, antes de mais nada, a um diário de impressões visuais que não buscam, necessariamente, um paralelo ou tradução para a linguagem verbal:

Todo esse "excerto do diário" não é contado, mas mos-
trado. Palavras e cartelas estão ausentes no filme. Os
quadros-fragmentos se ligam uns aos outros visualmente
e coincidem com os encadeamentos semânticos. É impos-
sível ler esse filme, e seria muito desejável que, durante
sua exibição, as frases visuais não fossem traduzidas
mentalmente em palavras (como é feito habitualmente
na exibição de filmes teatrais-atuados) [...] (VIÉRTOV,
2008, p. 154-155)

Em outra ocasião, ao dizer que o cinegrafista "revela os momentos mais interessantes de seu trabalho não por meio de palavras, mas por meio de uma cine-linguagem absoluta" (VIÉRTOV, 2008, p. 150), Viértov ressalta mais uma vez o caráter visual do diário apresentado. É nesse sentido que o cineasta talvez compreendesse não haver contradição entre um filme se apresentar como apartado "da linguagem do teatro e da literatura" e, simultaneamente, como um "excerto do diário de um cinegrafista". Sem se configurar em cartelas - como no diário de viagem de O Topo do Mundo: Expedição a Pamir (dir. Vladímir Erofêiev, 1928)17—, o diário construído por Viértov é certamente mais elusivo. E aqui podemos lançar uma série de questões: uma vez que o subtítulo foi atribuído pelo cineasta - que, apesar de ser o "autor central" do filme, não foi responsável pela tomada das imagens - será que estamos realmente diante do excerto do diário de um cinegrafista? E, ainda, seria esse o diário de um cinegrafista?

17 Apesar das diferenças entre os trabalhos, me parece que tanto o filme de Erofêiev quanto Sal para a Svanécia (dir. Mikhail Kalatôzov, 1930) - cujo roteiro foi escrito em parceria com o lefista Serguei Tretiakóv - travam um diálogo mais estreito com a ideia de "literatura do fato" tal como discutida pela Lef do que os filmes de Viértov. 


\section{Construindo um diário coletivo}

Nos sucintos créditos iniciais do filme, Mikhail Kaufman, o principal operador em cena (e, de fato, o responsável por muitas das tomadas) é destacado como diretor de fotografia, mas os espectadores são deixados com uma dúvida: quem seria, afinal, o "homem com a câmera" a registrar o trabalho do "homem com a câmera"? A resposta é que, na realidade, havia homens com a câmera: Borís Tsêitlin, Konstantín Kuliáiev e Gueórgui Khimtchiénko foram os três cinegrafistas adicionais do filme, sendo Tsêitlin o provável responsável por filmar o trabalho de Kaufman (MACKAY, 2013, p. 15). Apesar de não incluir essas informações nos créditos, Viértov sugeriu em um de seus pronunciamentos que o "cinegrafista do cinegrafista" seria um dos temas centrais da obra: "Basicamente, o filme discute três temas: a vida na filmagem, a vida na tela e a vida na vida. E ainda mais dois temas: O homem com a câmera observando a vida, e O homem com a câmera observando o homem com a câmera" (VIÉRTOV, 2008, p. 151). Isso nos leva a uma nova pergunta: afinal, a qual cinegrafista se refere o "excerto do diário de um cinegrafista"?

Trata-se, na realidade, de uma pergunta retórica. Uma vez inscrito nos créditos iniciais, ainda que possa ter nascido como simples "moldura" ou ainda como uma formulação que "sobrara" do título de um projeto anterior, o "excerto do diário de um cinegrafista" acaba por se tornar mais um elemento da já mencionada mise-en-abyme viertoviana. Se possui um sentido diegético, atribuindo um título à jornada do cinegrafista-em-cena, ele simultaneamente se refere às impressões visuais coletadas tanto por Kaufman quanto por Tsêitlin/Kuliáev/Khimtchiénko. Mas há ao menos mais dois participantes fundamentais nesse jogo: o material filmado é, por sua vez, organizado por Elizaviêta Svílova, que desempenha (tanto em cena quanto fora de cena) um papel essencial na transformação do "diário em filme" em "filmediário" - inclusive trabalhando com imagens de si mesma nesse processo. E há, evidentemente, a participação de Viértov enquanto "autor-líder do experimento", operando em todas as fases de elaboração do filme.

Parece-me que estamos diante de um caso daquilo que David E. James (2013, p. 176) identifica como "dispersão paralela da autoria", presente quando "o autor do diário inclui imagens feitas por outros". Todos podem ser vistos, em alguma medida, como coautores do diário: Kaufman ao se colocar na posição de "sujeito dividido in situ entre performance [diante da câmera] e registro [atrás da câmera]"; os demais cinegrafistas, ao filmarem Kaufman e produzirem também suas próprias impressões; Svílova ao se dividir entre performance e montagem do material, e Viértov ao coordenar todos os 
processos e, em última instância, decidir atribuir ao filme o subtítulo "excerto do diário de um cinegrafista" - gesto nada trivial se optarmos por considerar que um filme-diário, parafraseando Robert A. Fothergill, é aquilo que uma pessoa produz ao afirmar "Estou filmando um diário"18.

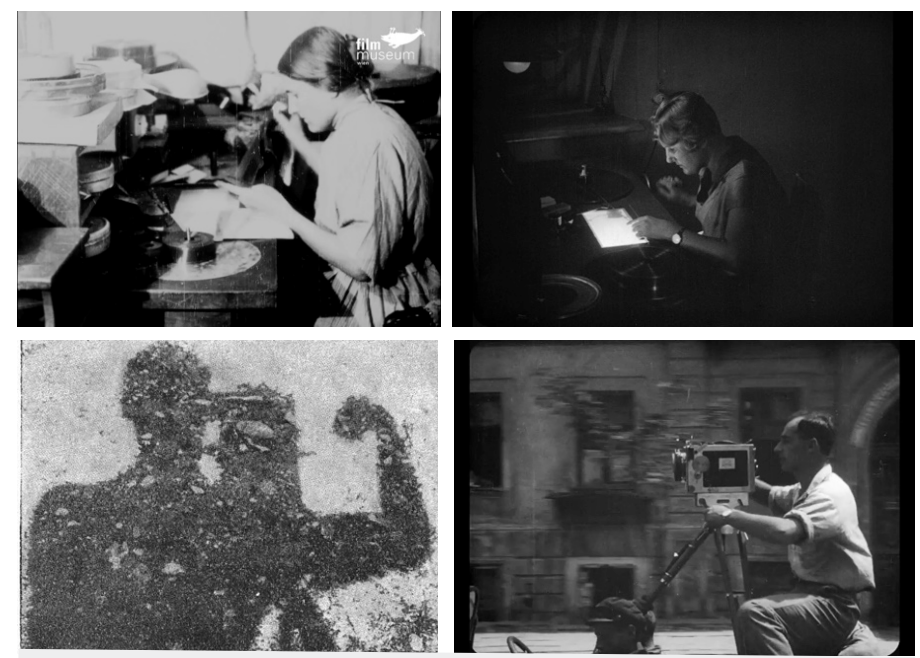

Figura 6. Acima, da esquerda para a direita: Elizaviêta Svílova na mesa de montagem em Kino-Pravda № 19 (1923). Figura. 7. Em O homem com a câmera (1929). Figura. 8. Abaixo: autorretrato de Mikhail Kaufman na revista "Soviétski Ekrán" n. 15, 7 de julho de 1925. Figura. 9. Kaufman em O homem com a câmera.

Assim como o registro do ato de filmar foi uma constante em muitos de seus projetos da década de 1920, Viértov também escreveria esboços de roteiros que giram em torno da representação de outras atividades do grupo CineOlho. Em um deles, os kinocs - o cineasta entre eles - seriam mostrados em uma reunião do grupo, preparando estudos fílmicos sobre temas como "crianças", "mãos", "pernas" e "olhos" (VIÉRTOV, 2004, p. 86)"19; em outro rascunho, dois cinegrafistas apresentariam ao conselho do grupo Cine-Olho os resultados de suas últimas expedições (VIÉRTOV, 2004, p. 92). Assim como O homem com a câmera, essas "reuniões roteirizadas" (e não- realizadas) poderiam ser aproximadas da ideia de "filme de produção", como obras

18 "Um diário é aquilo que uma pessoa escreve quando diz, 'Estou escrevendo no meu diário'" (FOTHERGILL apud JAMES, 2013, p. 175).

19 "1. A kinoc-observadora Svílova conclui a escolha de fragmentos para o tema 'mãos'. 2. O kinocobservador Zótov é designado para a observação sobre o tema 'pernas'. 3. Svílova a caminho da reunião dos kinocs (mãos pelo caminho). 4. O kinoc-cinegrafista Kaufman se apressa para a reunião [...] 7. Reunião dos kinocs [...]". 
didáticas sobre o próprio método de trabalho do grupo. Mas sugiro que podemos encará-las, também, como parte da construção de um diário coletivo dos kinocs, uma vontade nem sempre concretizada que teria encontrado em $O$ homem com a câmera sua mais plena expressão.

Talvez pudéssemos falar em um "diário profissional" do grupo, uma vez que, seja na décima nona edição de Kino-Pravda (1923) ou em O homem com a câmera, o que vemos é a Montadora, e não necessariamente Elizaviêta Svílova [Figuras 6 e 7]; vemos o Cinegrafista, e não Mikhail Kaufman [Figuras 8 e 9] (ainda que ele já então fosse uma figura célebre na imprensa por suas façanhas com a câmera) ${ }^{20}$. De fato, não estamos diante do registro da esfera íntima de suas vidas: como afirmou Viértov em uma das sessões do filme, o diário é compreendido sobretudo como um diário de trabalho, como "exemplos do trabalho do cinegrafista fora do estúdio" (VIÉRTOV, 2008, p. 155). De toda forma, parece ter havido uma preocupação sistemática em tematizar (e, eventualmente, documentar) em filme a atuação dos kinocs, esboçando ao longo dos anos um retrato, ainda que fragmentário, do grupo Cine-Olho. Um retrato que comporta, inclusive, referências e "piadas internas" ao próprio grupo: em 1923, os kinocs haviam sido chamados de "sapateiros" por um crítico insatisfeito com seus trabalhos; dois anos depois, o filme CineOlho: A vida apanhada de surpresa seria premiado na Exposição Internacional de Artes Decorativas e Industriais em Paris. Não por acaso, em O homem com a câmera vemos o cinegrafista refletido no espelho de uma vitrine com os dizeres "Engraxate especialista de Paris" [Figura 10].

Ademais, a noção de um diário de grupo voltado primariamente à sua atuação profissional (e não apenas à expressão íntima de suas subjetividades) parece coadunar com a ideia central de Jochen Hellbeck de que muitos diários da era soviética podem ser vistos como "ferramentas ativas" (HELLBECK, 2006, p. 5). Hellbeck nota que "a preocupação com a transformação de si mesmo" possuía raízes no próprio discurso da revolução de 1917, dando origem a um projeto político que enxergava o exercício da autoreflexão (e de escrita da própria biografia) como uma forma de o autor compreender seu papel no novo regime e avaliar suas contribuições. Como afirma Hellbeck, "falar e escrever sobre si mesmo haviam se tornado atividades intensamente politizadas": mesmo que muitos diários soviéticos fossem "distintamente introspectivos", essa introspeção "não estava ligada 
a propósitos individualistas", mas revelavam, antes, "um desejo de se inscrever em sua ordem social e política", de "se realizar como sujeitos históricos definidos por sua aderência ativa a uma causa revolucionária comum" (Idem, p. 4-7). Talvez seja essa uma possível chave de compreensão para a forma como Viértov enxergava a participação em cena do grupo Cine-Olho em seus trabalhos: a prática autorreflexiva como registro da participação ativa dos kinocs na transformação do país por meio de seu campo específico de atuação - a realização cinematográfica.

Curiosamente, o "autor-líder do experimento" é uma das figuras menos vistas nesse diário. Em sua presença em cena, Viértov está mais próximo de Hitchcock do que de Mekas; suas aparições são cameos fugazes, quase imperceptíveis para os menos atentos: um passageiro em um bonde em movimento, um dos olhos sobrepostos à lente da câmera ${ }^{21}$. Se em algumas edições de Kino-Pravda o cineasta fizera participações mais desinibidas [Figura 11]22, é discreta sua presença física em 0 homem com a câmera. Sintomático, aliás, é o fato de fotografias de Mikhail Kaufman serem até hoje, com alguma frequência, creditadas como retratos de Viértov²3.
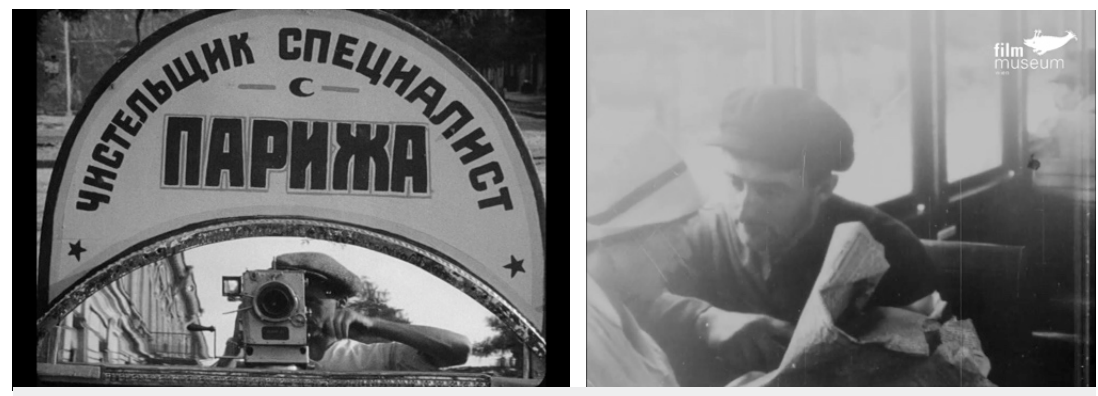

Figura. 10. À esquerda, a placa "Engraxate especialista de Paris" emoldurando o cinegrafista em O homem com a câmera. Figura. 11. À direita,Viértov em cena de Kino-Pravda Nº 8 (1922).

21 A identificação de Viértov como passageiro de um bonde em O homem com a câmera é feita por Graham Roberts (ROBERTS, 2000, p. 61), que por sua vez atribui a Yuri Tsivian a informação de que o olho sobre a íris da câmera seria de Viértov.

22 Me refiro aqui sobretudo à sua presença, ao lado de outros kinocs, em Kino-Pravda N 8 (15 de agosto de 1922). Além de uma aparição rápida, de costas e apoiado em uma janela, Viértov protagoniza uma pequena cena em um bonde, comprando um jornal e discutindo-o com uma passageira [Figura 11]. É possível também ver Viértov (apenas de perfil e de costas) em Kino-Pravda No 1 (5 de junho de 1922), embarcando em um avião Junkers.

23 Uma simples busca de imagens no Google pelo nome "Dziga Vertov" (feita em 23/03/2021) é reveladora: dentre os primeiros resultados, muitos consistem no mesmo autorretrato de Mikhail Kaufman, por vezes identificado como Viértov. 
Apesar disso, a autorrepresentação é tema recorrente em diversos de seus projetos, e não apenas como metaexploração do aparato cinematográfico. Mackay (2018, p. 214) nota que um de seus primeiros roteiros de filmagem se intitula "A Missão do Camarada Viértov, Instrutor de Filmagens, sob as ordens do Camarada Kojévnikov, Comandante do Exército Vermelho" (VIÉRTOV, 2004, p. 31), estabelecendo desde cedo “o motivo da jornada do cineasta ou do cinegrafista" em sua carreira, ainda que o filme provavelmente não tenha sido realizado. Já o roteiro ficcional nunca filmado "Projeto de roteiro a ser filmado durante a viagem do trem de agitação Soviétski Kavkáz" (VIÉRTOV, 2004, p. 44-47) é protagonizado por um acanhado chefe da seção cinematográfica de um trem de agitação cujo modelo é, sem dúvidas, o próprio Viértov. Significativo também é o fato de um momento definido por ele como central para sua compreensão do cinema ser também, em anos posteriores, descrito em termos autobiográficos. Por volta de 1919, o cineasta teria pedido que o filmassem, em câmera lenta, saltando do alto de uma construção anexa ao Comitê de Fotografia e Cinematografia; nos anos 1930, Viértov atribuiria o nascimento do conceito de "Cine-Olho" ao instante em que, assistindo ao material de seu salto, ele teria percebido que a câmera lenta lhe permitia analisar seus processos mentais, suas hesitações e as sutilezas do movimento de seu próprio corpo quando projetado na tela. Mais tarde, em 1947, o cineasta definiria esse momento inaugural como um “autorretrato em câmera lenta” (VIÉRTOV, 1996, p. 167).

\section{Conclusão: um filme autobiográfico?}

É fato que, na década de 1920, Viértov não discute a fundo o possível caráter pessoal ou íntimo de seus trabalhos. Como vimos, mesmo o "excerto de um diário" é colocado em referência ao cinegrafista, e não ao próprio realizador, e o "diário coletivo" do grupo Cine-Olho parece se ater, a princípio, a uma documentação de sua atuação profissional. No entanto, há um comentário especialmente instigante tecido por um crítico contemporâneo do cineasta, destoante da percepção hegemônica da crítica à época e que tampouco parece ter atraído a atenção de estudiosos posteriores da obra de Viértov. Escrevendo em 1929, Khrisanf Kherssónski não só considerou o "excerto do diário de um cinegrafista" um elemento importante para sua análise de o homem com a câmera como descartou o "de um cinegrafista" do subtítulo e o interpretou não como o diário de um personagem, mas do próprio cineasta. Em um primeiro texto (KHERSSÓNSKI, 2004, p. 329), o crítico definiu 
o filme como "inteiramente autobiográfico para Viértov, tanto em sua trama como em sua linguagem". Em um segundo artigo, foi além:

\begin{abstract}
Viértov retornou o cinema à sua infância, a seu estado primitivo; ele restaurou nele o sentimento de arrebatamento diante da simples visão de um cavalo correndo ou de um homem se lavando. O filme $O$ homem com a câmera, o mais típico e, poderíamos dizer, íntimo dos trabalhos de Viértov, nos diz isso de maneira eloquente. Ele é completamente autobiográfico. São páginas de um diário nas quais a quintessência da experiência visual do artista é envolta na mais sincera expressão de sua visão de mundo. E é por isso que é precisamente a partir de $O$ homem com a câmera que podemos compreender toda a trajetória do trabalho de Viértov, e traçar algo como uma folha de balanço... (KHERSSÓNSKI, 2004, p. 334)
\end{abstract}

Há muito a ser depreendido desse comentário de Kherssónski. Em primeiro lugar, a imagem da "folha de balanço" parece especialmente apropriada diante das inúmeras conexões formais e temáticas que 0 homem com a câmera estabelece com trabalhos anteriores de Viértov, da série Kino-Pravda a $O$ décimo primeiro ano. Em segundo lugar, a associação entre autobiografia e o cinema de Viértov é bastante inusual no contexto soviético do período. A rigor, até mesmo a ideia de um cinema autobiográfico soa original, a despeito da proliferação de narrativas autobiográficas no período (HELLBECK, 2006, p. 7): por mais que críticos como Óssip Brik e Viktor Chklóvski apontassem a crescente "poetização" dos filmes de Viértov, ela era discutida sobretudo no campo das figuras retóricas empregadas, e não no campo da inscrição de sua subjetividade, ao menos não em termos tão diretos quanto os de Kherssónski. Ao destacar que a "experiência visual do artista é envolta na mais sincera expressão de sua visão de mundo", o crítico parece indicar o quanto o método viertoviano não é, de modo algum, avesso à individualidade do realizador.

Retorno agora ao húngaro Béla Balázs, pois também ele tivera percepção similar ao escrever sobre o cineasta em termos que, por sua vez, nos remetem também às "notas e esboços" que Mekas realizaria décadas mais tarde:

[...] O poeta nos guiando com sua câmera não é um poeta narrativo. Ele se parece mais com um poeta lírico que produz notas e esboços ópticos. Ao organizá-los em uma montagem, ele deve, no entanto, se assegurar de estar criando uma imagem viva, uma atmosfera viva. Esses filmes podem não possuir uma linha narrativa, mas eles certamente possuem um protagonista. Ele é simplesmente "o homem 
com a câmera", para citar o filme mais característico de Vertov [...] Ele próprio permanece invisível. Mas tudo o que vê, ele nos mostra. Tudo o que o move nos faz sentir sua emoção. Assim é o filme lírico (BALÁZS, 2010, p. 153).

Neste subcapítulo de O espírito do Cinema, intitulado "Cine-olho", Balázs não se refere ao trabalho do cineasta como um diário, mas ocorre algo curioso. 0 subcapítulo que se inicia logo no parágrafo seguinte se intitula precisamente "Diário e Autobiografia", e as breves especulações de Balázs sobre as potencialidades desses gêneros parecem decorrer de seu comentário prévio sobre o trabalho de Viértov: “Uma personalidade que se torna visível apenas através de seu modo de ver. Será que isso não serve de receita para um filme-diário ou para um filme-autobiografia?" (BALÁZS, 2010, p. 153). Pode estar aí mais um possível caminho para a compreensão da forma como Viértov, mesmo "oculto", inscreve sua subjetividade "por meio da criação de um estilo pessoal de filmagem" (JAMES, 2013, p. 174) e montagem.

O homem com a câmera não é, por óbvio, apenas um filme-diário ou uma obra meramente autobiográfica. Mas me parece que tanto o filme em si como a trajetória de Viértov até sua realização, compreendida com a inclusão de seus inúmeros projetos não realizados, apontam para a validade de explorarmos essa chave de leitura sobre o trabalho. Como busquei mostrar, referências a diários podem ser encontradas em diferentes filmes e escritos do cineasta, indicando que a forma diarística estava em sua órbita de atenção. Sua inserção em O homem com a câmera, quando conjugada à consistente prática de representação da atividade profissional do grupo Cine-Olho, não parece meramente fortuita. E se Viértov de fato não acentua os possíveis elementos autobiográficos de seu trabalho, não podemos esquecer que, buscando uma definição para o Cine-Olho em 1929 (VIÉRTOV, 2008, p. 160), o kinoc conclui uma de suas principais fórmulas com um verbo conjugado na primeira pessoa do singular: "Montar, extrair com a câmera o mais característico, o mais lógico: organizar os fragmentos extraídos da vida em uma ordem semântico-visual rítmica, em uma fórmula semântica- visual, em um extrato de: VEJO!".

Luis Felipe Gurgel Ribeiro Labaki é cineasta, pesquisador e tradutor do idioma russo. É doutorando no Programa de Pós-Graduação em Meios e Processos Audiovisuais da Escola de Comunicações e Artes da 
Universidade de São Paulo (PPGMPA-ECA-USP). Mestre pelo mesmo programa, defendeu, em 2016, sua dissertação "Viértov no papel: um estudo sobre os escritos de Dziga Viértov".

luis.labaki@usp.br

lulabaki@hotmail.com

\section{Referências}

Arquivos consultados:

RGALI (Rossíski Gossudárstvenni Arkhiv Literatúry i Iskússtva) [Arquivo Estatal Russo de Literatura e Arte): f.2091 (Dziga Viértov), op.2, ed. khr. 235 e 236.

\section{Bibliografia}

BALÁZS, B. Béla Balázs: Early Film Theory: "Visible man" and "The spirit of film". Nova York, Oxford: Berghahn Books, 2010.

BRIK, O. Razlojênie siujéta. in: TCHUJÁK, N.F (Org.). Literatura fakta: piérvi sbórnik materiálov rabótnikov LEFa. Moscou: Zakhárov, 2000. p. 226-229.

DICKERMAN, L. The fact and the photograph. October, $n^{\circ} 118,2006 . p .132-152$.

HELLBECK, J. Revolution on my mind: Writing a Diary Under Stalin. Cambridge; Londres: Harvard University Press, 2006.

HICKS, J. Dziga Vertov: Defining Documentary Film. Londres: I.B. Tauris, 2007.

JAMES, D. E. Diário em filme/ Filme-diário: prática e produto em Walden, de Jonas Mekas. In: MOURÃO, P. (Org.). Jonas Mekas. São Paulo: Pró-Reiteoria de Cultura e Extensão Universitária - USP, 2013. p. 165-206.

KAUFMAN, M. S apparátom v stiép. Soviétski Ekrán, № 23 (33), $1^{\circ}$ de setembro de 1925. p. 13.

KHERSSÓNSKI, K. Man with a movie camera. In: TSIVIAN, Y. (Org.) Lines of Resistance: Dziga Vertov and the Twenties Pordenone: Le Giornate del cinema muto, 2004. p. 327-331. . Man with a movie camera. In: Lines of Resistance, p. 333-335.

MACKAY, J. Film Energy: process and metanarrative in Dziga Vertov's The eleventh year (1928). October, n.121, 2007, p. 41-78.

. Man with a Movie Camera: An Introduction. 2013. Disponível em: <https://bit. ly/3fMDoOm>. Acesso em: 24 mar. 2021.

Dziga Vertov: life and work. Volume 1 (1896-1921). Boston: Academic Studies 
Press, 2018.

MICHELSON. The Man with the Movie Camera: From Magician to Epistemologist. Artforum 10, n 7 (Março de 1972), p .60-72

OGNIÓV, N. Diário de Kóstia Riábtsev. São Paulo: Editora 34, 2017.

PETRIČ, V. Constructivism in film: the man with the movie camera, a cinematic analysis. Cambridge: Cambridge University Press, 1987.

ROBERTS, G. The man with the movie camera. Londres, Nova York: I.B. Tauris, 2000.

SARKISOVA, O. Across one sixth of the world: Dziga Vertov, Travel Cinema, and Soviet Patriotism. October, 121, 2007, p. 19-40.

SITNEY, P. A. Visionary film: the american avant-garde, 1943-2000, terceira edição. Nova York: Oxford University Press, 2002.

TSIVIAN, Y. Dziga Vertov and His Time. In: Lines of resistance: Dziga Vertov and the Twenties, p. 1-28.

VIÉRTOV, D. Tvórtcheskaia kártotchka. Kinoviédtcheskie Zapíski, №29, 1996. p. 161-192. . Kogdá snimát drug drúga búdete, ne snimáites bez kinoapparátov... Kinoviédtcheskie Zapíski, № 29, 1996. p. 193-196.

. Komandiróvka instrúktora siômok tov. Viértova v rasporiajênie kománduiuschego Krásnoi Ármiei tov. Kojévnikova. In: VIÉRTOV, D.; DERIÁBIN, A. (Org.). Dziga Viértov. Iz Nasliêdia. Tom 1. Dramaturguítcheski Ópyty. Moscou: Eisenstein-Tsentr, 2004, p. 31-34. Sem data, escrito não antes de abril de 1919.

Proekt stsenária, prednaznátchennogo k siômke vo vrêmia poiézdki aguitpôezda Soviétski Kavkáz. In: Iz Nasliêdia. Tom 1, p. 44-47. Datado de 2 de maio de 1920.

. [Rúki, Nógui, Glazá, Tiémy]. In: Iz Nasliêdia. Tom 1, p. 79-88. Sem data, escrito não antes de 1922 e não depois de 1924.

. Zassedânie soviéta "Kino-Gláz". In: Iz Nasliêdia. Tom 1, p. 92-93. Sem data, escrito não depois de 1925.

. [Porôgui]. In: Iz Nasliêdia. Tom 1, p. 119-120; p. 489. Datado de 20 de maio de 1927.

. Tcheloviék s kino-apparátom (zrítelnaia simfônia). In: Iz Nasliêdia. Tom 1, p. 123-126. Datado de 19 de março de 1928.

. Galerêia kinoportriétov. In: Iz Nasliêdia. Tom 1, p. 449. Datado de 25 de agosto de 1944.

. Kinoki, Perevorót. In: VIÉRTOV, D.; ICHÊSVKAIA, S. (Org.); KRUJKÔVA, D. (Org.). Dziga Viértov. Iz Nasliêdia. Tom 2. Statí i Vystupliênia. Moscou: Eisenstein-Tsentr, 2008, p. 35-43. 
Publicação original: Lef, N³, 1923.

Odínnadtsati (Otrívki iz siômotchnogo dnevniká). In: Iz Nasliêdia. Tom 2, p. 140. Publicação original: Soviétski Ekrán, 1928, № 9 (28 de fevereiro).

Tcheloviék s kinoapparátom, absoliútnaia kinópís i Rádio-Glaz (Zaiávka ávtora). Iz Nasliêdia. Tom 2, p. 146-147. Datado de 6 de novembro de 1928.

Piérvaia soviétskaia "fílma bez slóv" (Tcheloviék s kinoapparátom). In: Iz Nasliêdia. Tom 2, p. 149. Publicação original: Pravda, 1928, $1^{\circ}$ de dezembro.

[Absoliútni kino-iazík]. In: Iz Nasliêdia. Tom 2, p. 150-154. Datado de 23 de janeiro de 1929.

. Tchetíre zadátchi Tcheloviéka s kino-apparátom. In: Iz Nasliêdia. Tom 2, p. 154-155. Datado de 1929.

Tcheloviék s kinoapparátom. Iz bessiêdi s D. V. In: Iz Nasliêdia. Tom 2, p. 156-157. Publicação original: Nóvi zrítel, 1929, № 5 (27 de janeiro). de 1929.

. [Chtô takôe Kino-Glaz]. In: Iz Nasliêdia. Tom 2, p. 157-163. Datado de 19 de fevereiro Otviét na voprôs “Pôniali li vách fílm v Berlíne?”. In: Iz Nasliêdia. Tom 2, p. 182-184. . Moi ráport. In: Iz Nasliêdia. Tom 2, p. 281-282. Publicação original: Izvêstia, 1934, 15 de dezembro.

[Vystupliênie o tvórtcheskom putí]. In: Iz Nasliêdia. Tom 2, p. 359-369. Datado de 26 de maio de 1946.

Artigo recebido em 29/03/2021 e aprovado em 15/06/2021. 